\title{
Comparison of the effects of Chinese herbs, probiotics and prebiotics with those of antibiotics in diets on the performance of meat ducks
}

\author{
J. Wang and H. Zhou ${ }^{1}$ \\ College of Animal Science and Technology, China Agricultural University \\ Yuanmingyuan West Road 2, Beijing, 100094, P.R. China
}

(Received 26 April 2006; revised version 6 October 2006; accepted 2 February 2007)

\begin{abstract}
This study was conducted to compare the effect of some additives on the performance of Pekin meat ducks. Three types of feed additives, Chinese herbs, probiotics and prebiotics, were supplemented separately to meat duck diets and compared with an antibiotic treatment group as well as with a group of non-supplemented birds. For a seven-week feeding trial, a total of 300 meat ducks were allotted to five treatments. The treatments were: non-supplemented, antibiotics, Chinese herbs, probiotics, and prebiotics. At the end of starter phase (weeks 0-2), the ducks on probiotics had the highest body weight $(\mathrm{P}<0.01)$, and during the last weeks (weeks 3-7) the ducks in all experimental groups grew faster than the negative controls $(\mathrm{P}<0.01)$. The feed conversion ratio (FCR) of the probiotics group was significantly lower than in the other groups during the whole experiment. Mortality was lowest in the Chinese herbs and antibiotics groups $(0 \%)$. The carcass characteristics study showed that every trait measured in this experiment was similar $(\mathrm{P}>0.05)$ in all groups. Overall, it can be inferred that supplementation of Chinese herbs, probiotics, prebiotics did not negatively affect meat duck performance and that these feed additives can replace antibiotics in Pekin meat duck diets.
\end{abstract}

KEY WORDS: meat duck, feed additive, performance, herbs

\section{INTRODUCTION}

Antibiotic feed additives have been used in livestock production for about 50 years (Dibner et al., 2005). They have played an important role in animal

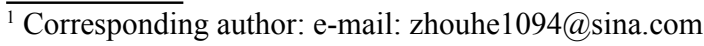


growth by helping animals avoid bacterial diseases. When antibiotics were used as growth promoters, they were said to improve daily weight gain by 3 to $9 \%$ and the feed conversion ratio by 4 to $8 \%$ with fewer scours problems (Hedde, 1984). They appeared to act by reducing the pathogenic bacteria load and modifying the microflora in the gut, increasing the availability of nutrients for the animal itself and reducing their availability to bacteria (Visek, 1978; Hedde, 1984). Low-level antibiotic additives added to livestock diets can help prevent illness and improve performance. However, their prolonged use has the potential to increase bacterial resistance and the level of drug residues in edible animal products. This will lead to the transfer of antibiotic resistance to human pathogens and will be harmful to human health (Kritas et al., 2005). Therefore, removing antibiotics from livestock feed additives and concern about human health increased the attention paid by scientists to these problems.

With the increasing insight into the potential promotion of gastrointestinal resistance and increase of residues in animal products by antibiotics, alternatives to them, such as herb extracts, prebiotics, probiotics and other feed additives, have been studied (Smoragiewicz et al., 1993; Zimmermann et al., 2001; Guo et al., 2004). Furthermore, due to the ban of most antibiotic growth promoters in Europe and the expected spread of this trend to the rest of the world in recent years, finding alternative means is becoming a major issue in animal production. In this context, the use of Chinese herbs, probiotics and prebiotics to increase meat duck production is receiving more attention. Although these additives have been studied and used in pigs, chickens and other animals, little is known about their effects on meat ducks. Considering that duck meat is a traditional Chinese delicacy and is becoming increasingly popular, it is therefore necessary to investigate the effects of feeding these additives to meat ducks on their body weight, feed conversion ratio and carcass characteristics and to determine the optimal antibiotic substitute in meat duck production.

\section{MATERIAL AND METHODS}

\section{Experimental birds}

Three hundred one-day-old unsexed Pekin meat ducks were weighed and randomly distributed into 5 groups with 4 replicates per group and 15 meat ducks per replicate. Each replicate was kept in a separate pen $(240 \times 150 \mathrm{~cm})$. The birds were kept on the floor and water vans were available. Starter feed was given in weeks $0-2$ and finisher rations for the remaining 5 weeks. Feed and water were offered ad libitum throughout the 7 weeks of the study period. 


\section{Poultry feeds}

Ten poultry feeds were used in the experiment. All feeds were isonitrogenous (starter CP 19.0\%, finisher CP 14.5\%) and isocaloric (starter ME $11.71 \mathrm{MJ} / \mathrm{kg}$, finisher ME $11.29 \mathrm{MJ} / \mathrm{kg}$ ) and only varied in the feed additives. Feed composition is shown in Table 1.

Table 1. Composition of meat duck starter and finisher feed used in the study

\begin{tabular}{lcc}
\hline Indices & Starter feed & Finisher feed \\
\hline Ingredients, \% & & \\
$\quad$ maize & 51.0 & 56.0 \\
soyabean meal & 29.0 & 16.2 \\
fish meal & 2.0 & \\
rapeseed meal & & 3.5 \\
wheat shorts & 9.3 & 9.6 \\
chaffed straw & 3.5 & 9.5 \\
talcum powder & 1.2 & 1.2 \\
dicalcium phosphate & 1.7 & 1.7 \\
NaCl & 0.3 & 0.3 \\
carrier (Bentonite) & 1.0 & 1.0 \\
Premix* & 1.0 & 1.0 \\
total & 100.00 & 100.00 \\
Calculated analysis, $g / k g$ & & \\
metabolizable energy, MJ/kg & 11.71 & 11.29 \\
crude protein & 190 & 145 \\
ether extract & 29 & 33 \\
crude fibre & 36 & 53 \\
Ca & 10.4 & 9.5 \\
total P & 7.1 & 6.4 \\
lysine & 11.0 & 7.5 \\
methionine+cystine & 8.0 & 6.3 \\
\hline
\end{tabular}

* provided the following supplementation per kg of diet, IU: vit. A 12,000; vit. $\mathrm{D}_{3} 3,120$; vit. E 85; mg: menadione sodium bisulphite 4; vit. $\mathrm{B}_{12}$ 0.07; riboflavin 10; Ca-pantothenate 44; niacin 60; Se 0.2; Fe 97; Mn 32; Zn 97; Cu 9

\section{Experimental protocol}

Meat ducks of various groups were given the following feeding treatment (Table 2). The quantity of each additive was determined according to the recommended quantity for chickens.

The vaccination schedule was uniform for all groups. Body weight gain and feed intake were recorded at the end of weeks 2, 5 and 7 . Feed consumption, health of the 
weight of the ducks given prebiotics (Group 4) was closer to the non-supplemented group. At the end of the week 7, the Chinese herbs group had the highest body weight but the difference did not reach statistical significance in respect to the antibiotics and probiotics groups. The four supplemented groups had significantly higher body weights than the non-supplemented group.

Table 3 also shows the feed conversion ratios of meat ducks on different treatments. The probiotics group had the highest feed intake per meat duck during weeks $0-2$ and was significantly higher than in other groups $(\mathrm{P}<0.05)$. Similar trends could be found in this phase on weight gain per meat duck and FCR. Also, the feed intake, weight gain and FCR of the Chinese herbs and prebiotics groups were similar or close to those of the antibiotics group. During weeks 3-7, the Chinese herbs group had the highest feed intake and weight gain per meat duck but did not have a better FCR. The probiotics group still had the lowest FCR in this phrase, which was clearly lower than the others.

Table 3. The production performance of meat ducks given various treatments of additives

\begin{tabular}{|c|c|c|c|c|c|c|c|}
\hline \multirow{2}{*}{ Treatments } & \multicolumn{5}{|c|}{ Group } & \multirow{2}{*}{$\mathrm{SEM}^{1}$} & \multirow{2}{*}{ Probability } \\
\hline & control & 1 & 2 & 3 & 4 & & \\
\hline \multicolumn{8}{|l|}{ Body weight, kg } \\
\hline at the end of $2^{\text {nd }}$ week & $0.53^{\mathrm{B}}$ & $0.55^{\mathrm{B}}$ & $0.54^{\mathrm{B}}$ & $0.58^{\mathrm{A}}$ & $0.54^{\mathrm{B}}$ & 0.008 & $\mathrm{P}<0.01$ \\
\hline at the end of $5^{\text {th }}$ week & $2.08^{\mathrm{C}}$ & $2.15^{\mathrm{Ab}}$ & $2.17^{\mathrm{Aa}}$ & $2.13^{\mathrm{B}}$ & $2.12^{\mathrm{B}}$ & 0.011 & $\mathrm{P}<0.01$ \\
\hline at the end of $7^{\text {th }}$ week & $3.18^{\mathrm{C}}$ & $3.23^{\mathrm{Ab}}$ & $3.26^{\mathrm{Aa}}$ & $3.25^{\mathrm{Aa}}$ & $3.21^{\mathrm{B}}$ & 0.023 & $\mathrm{P}<0.01$ \\
\hline \multicolumn{8}{|l|}{$0-2$ weeks } \\
\hline feed intake/meat duck, $\mathrm{kg}$ & $0.80^{\mathrm{b}}$ & $0.80^{\mathrm{b}}$ & $0.82^{\mathrm{b}}$ & $0.84^{\mathrm{a}}$ & $0.80^{\mathrm{b}}$ & 0.011 & $\mathrm{P}<0.05$ \\
\hline weight gain/meat duck, $\mathrm{kg}$ & $0.47^{b}$ & $0.48^{\mathrm{b}}$ & $0.49^{\mathrm{b}}$ & $0.51^{\mathrm{a}}$ & $0.48^{\mathrm{b}}$ & 0.008 & $\mathrm{P}<0.05$ \\
\hline FCR & $1.72^{\mathrm{b}}$ & $1.67^{\mathrm{ab}}$ & $1.69^{\mathrm{ab}}$ & $1.64^{\mathrm{a}}$ & $1.69^{\mathrm{ab}}$ & 0.021 & $\mathrm{P}<0.05$ \\
\hline \multicolumn{8}{|l|}{ 3-7 weeks } \\
\hline feed intake/meat duck, $\mathrm{kg}$ & $9.74^{\mathrm{B}}$ & $9.70^{\mathrm{B}}$ & $9.95^{\mathrm{A}}$ & $9.57^{\mathrm{B}}$ & $9.67^{\mathrm{B}}$ & 0.090 & $\mathrm{P}<0.01$ \\
\hline weight gain/meat duck, $\mathrm{kg}$ & $2.64^{\mathrm{c}}$ & $2.69^{b}$ & $2.72^{\mathrm{a}}$ & $2.67^{\mathrm{b}}$ & $2.67^{\mathrm{b}}$ & 0.029 & $\mathrm{P}<0.05$ \\
\hline FCR & $3.68^{\mathrm{b}}$ & $3.61^{\mathrm{ab}}$ & $3.66^{\mathrm{b}}$ & $3.58^{\mathrm{a}}$ & $3.62^{\mathrm{ab}}$ & 0.043 & $\mathrm{P}<0.05$ \\
\hline Mortality at the end of $7^{\text {th }}$ weeks, $\%$ & 3.33 & 0 & 0 & 1.67 & 3.33 & & \\
\hline
\end{tabular}

Mortality in the different treatment groups at the end of the $7^{\text {th }}$ week was calculated. Group 2 (antibiotics) and Group 3 (Chinese herbs) were the lowest $(0 \%)$, showing that Chinese herbs have a beneficial effect on preserving meat ducks' health. Group 3 (probiotics) and Group 4 (prebiotics) had slightly lower survival rates, but these were higher or close to the control value.

As shown in Table 4, no significant differences were observed among all treatments in all carcass traits measured in our experiments $(\mathrm{P}>0.05)$. This 
indicates that these feed additives did not have a negative effect on meat ducks' carcass characteristics.

Table 4 . The carcass characteristics of meat ducks given various additives, $\% \mathrm{BW}$

\begin{tabular}{|c|c|c|c|c|c|c|c|}
\hline \multirow{2}{*}{ Treatments } & \multicolumn{5}{|c|}{ Group } & \multirow{2}{*}{ SEM* } & \multirow{2}{*}{ Probability } \\
\hline & control & 1 & 2 & 3 & 4 & & \\
\hline Carcass $^{1}$ yield & 90.07 & 91.23 & 91.30 & 91.10 & 90.93 & 0.79 & NS \\
\hline Half net ${ }^{2}$ weight & 83.14 & 84.61 & 85.49 & 84.03 & 83.87 & 0.52 & NS \\
\hline Total net ${ }^{3}$ weight & 75.21 & 75.93 & 77.51 & 76.72 & 75.89 & 0.67 & NS \\
\hline Breast & 10.15 & 11.19 & 11.57 & 11.26 & 10.69 & 0.24 & NS \\
\hline Leg & 10.89 & 11.29 & 11.55 & 11.78 & 10.56 & 0.26 & NS \\
\hline Abdominal fat & 1.57 & 1.65 & 1.63 & 1.50 & 1.58 & 0.07 & NS \\
\hline
\end{tabular}

* standard error of the mean

${ }^{1}$ carcass yield was taken after removing the blood and feather

${ }^{2}$ half net weight was taken after removing the giblets i.e. trachea, oesophagus, craw, intestines, spleen, pancreas, genitalia

${ }^{3}$ total net weight was taken after removing the giblets i.e. heart, liver, gizzard, abdominal fat from half net weight NS means no significant differ

\section{DISCUSSION}

Chinese herbs are a part of traditional Chinese medicine. Natural medicinal products originating from fungi and herbs have been used as feed additives for farm animals in China for centuries and show many medicinal properties, such as antimicrobial activity, immune enhancement, and stress reduction (Wang et al., 1998). Because of their natural origin, their use in animal diets will not lead to bacterial resistance or cause concern over drug residues and toxicity ( $\mathrm{Lu}$ et al., 2003). Chinese herbs can improve the metabolism, growth performance and reproduction of animals. At the same time they can prevent and cure many animal diseases. This practice is also economically feasible because these herbs are very inexpensive and their sources are abundant. It can be seen from this experiment that Chinese herbs can clearly promote the body weight gain of meat ducks throughout the whole growth period as compared with the non-supplemented group. FCR, mortality and carcass characteristics were similar or close to the antibiotic group. The results also agree with Jamroz et al. (2002) who observed improvements in daily gain and feed conversion ratio in poults fed with a diet supplemented with a plant extract. From Table 4 it is also evident that the Chinese herbs group had the highest feed intake during weeks 3-7. This may owe to some component of Chinese herbs that could enhance an animal's appetite or increase the palatability of diets, thereby increasing feed intake. In summary, Chinese herbs have a positive effect on meat duck performance and can be considered a substitute for antibiotics. 
The term probiotic, introduced in the mid 1950's, is derived from Greek and means "for life." Although there are a number of definitions for this term, probiotics are generally defined as live microorganisms that improve animal health or wellbeing by modifying the intestinal microflora (Briczinski, 2005). Ingesting adequate amounts of probiotics can help form the proper bacterial balance and improve gut health, prevent or cure some diseases and promote livestock growth and production (Fuller, 1989; Smoragiewicz et al., 1993). In this study, a preparation of mixed cultures of Lactobacillus acidophilus and Bacillus subtilis was used. Our results show that the weight of meat ducks on probiotics at the end of week 2 was significantly higher than in other groups, but by week 7 this predominance was lost and these birds' body weights were just under that in the Chinese herbs group. Cavazzoni (1998) who used Bacillus coagulans as a probiotic suggested that the mean body weight of chickens on day 49 was up to $7.2 \%$ higher than in the no additive group. Thus, it can be deduced that beneficial effects might have been more pronounced in our study if the quantity of the probiotics had been increased during weeks 3-7. Furthermore, the FCR of the probiotics group was better when compared with the antibiotics group and mortality was lower than in unsupplemented controls. It can be seen that the preparation of mixed cultures of Lactobacillus acidophilus and Bacillus subtilis as probiotics were superior in terms of weight gain and FCR to antibiotics in meat ducks and can be proposed as a replacer for antibiotics.

Prebiotics are defined as nondigestible food ingredients that beneficially affect the host by selectively stimulating the growth or activity of bacterial species in the colon, thus benefiting host health (Gibson et al., 1995). Oligosaccharides have been used as prebiotics to influence the composition of the bacterial populations in the large intestine of a number of animal species (Grizard et al., 1999; Rycroft et al., 2001). Previous reports suggest that mannose-oligosaccharide (MOS) supplementation resulted in improved production in terms of body weight gain and feed conversion (Parks et al., 2001) and significant improvement in antibody responses (Cotter et al., 2000). In the present experiment, the improvement of body weight (at the end of $7^{\text {th }}$ week) was $+0.99 \%$ and the feed conversion ratio ( $3 \sim 7$ weeks) was $-1.63 \%$ relative to the negative control and a distinct decrease in mortality was not observed. This result did not achieve the level reported by Scflon et al. (2002) who showed that broiler chicken fed MOSsupplemented diets improved 49 -d body weight by $+2.7 \%$, feed conversion ratio by $-2.4 \%$, and mortality by $-9.7 \%$ relative to results of non-supplemented control diets. In our experiment, we may have not given a sufficient quantity of MOS during the growth period or there were some other factors that affected the ducks' response. But the results still indicate that prebiotics do not negatively affect the growth performance of meat ducks and that its effects need further study.

Taken together, the present results suggest that Chinese herbs, probiotics and prebiotics can be used by poultry farmers or feed manufacturers for improving 
performance instead of using antibiotics in meat duck diets without compromising duck health or productivity. In light of these results, the optimum quantity of these additives and their other effects on meat ducks merit further investigation.

\section{REFERENCES}

Briczinski B.P., 2005. Culturally speaking: pre, pro and other biotics. Dairy Foods 106, 42

Cavazzoni V., Adami A., Castrovilli C., 1998. Performance of broiler chickens supplemented with Bacillus coagulans as probiotic. Brit. Poultry Sci. 39, 526-529

Cotter P.F., Malzone A., Paluch B., Lilburn M.S., Sefton A.E., 2000. Modulation of humoral immunity in commercial laying hens by a dietary prebiotic. Poultry Sci. 79, Suppl. 1, 38 (Abstr.)

Dibner J.J., Richards J.D., 2005. Antibiotic growth promoter in agriculture: history and mode of action. Poultry Sci. 84, 634-643

Fuller R., 1989. Probiotics in man and animals. J. Appl. Bacteriol. 128, 365-378

Gibson R.G., Roberfroid M.B., 1995. Dietary modulation of the human colonic microbiota: Introducing the concept of prebiotics. J. Nutr. 125,1401-1412

Grizard D., BarthomeufC., 1999. Non-digestible prebiotics used as prebiotic agents: Mode of production and beneficial effects on animal and human health. Reprod. Nutr. Develop. 39, 563-588

Guo F.C., Kwakkel R.P., Soede J., Williams B.A., Verstegen M.W., 2004. Effect of a Chinese herb medicine formulation, as an alternative for antibiotics, on performance of broilers. Poultry Sci. 45, 793-797

Hedde R.D., 1984. Nutritional aspect of virginiamycin in feeds. In: M. Woodbine (Editor). International Symposium on Antibiotics in Agriculture: Benefits and Malefits. Antimicrobials and Agriculture. Butterworths, London, pp. 359-368

Jamroz D., Kamel C., 2002. Plant extracts enhance broiler performance. J. Anim. Sci. 80, Suppl. 1, 4 (Abstr.)

Kritas S.K., Morrison R.B., 2005. Evaluation of probiotics as a substitute for antibiotics in a large pig nursery. Vet. Rec. 156,447-448

Lu X.T., Dai J.H., Liao M., 2003. Advancement of studies on immuno-regulative activities of polysaccharides (in Chinese). Prog. Vet. Med. 24,10-12

Parks C.W., Grimes J.L., Ferket P.R., Fairchild A.S., 2001. The effect of mannanoligosaccharides, bambermycins, and virginiamycin on performance of large white male market turkeys. Poultry Sci. 80, 718-723

Rycroft C.E., Jones M.R., Gibson G.R., Rastall R.A., 2001. A comparative in vitro evaluation of the fermentation properties of prebiotic oligosaccharides. J. Appl. Microbiol. 91, 878-887

Scflon A.E., Sims M.D., Collctt S., 2002. Evaluation of of Bio-Mos in commercial broiler chickens. Poultry Sci. 80, Suppl. 1, 77 (Abstr.)

Smoragiewicz W., Bielecka M., Baouchowski A., Boutard A., Dubeau H., 1993. Les probiotiques. Can. J. Microbiol. 39, 1089-1095

Visek W.J., 1978. The mode of growth promotion by antibiotics. J. Anim. Sci. 46, 1447-1469

Wang R.J., Li D.F., Bourne S., 1998. Can 2000 years of herbal medicine history help us solve problems on the year 2000? Proceedings of Alltech's $14^{\text {th }}$ Annual Symposium. University Press, Nottingham (UK), pp. 273-291

Zimmermann B., Bauer E., Mosenthin R., 2001. Pro- and prebiotics in pig nutrition: Potential modulators of gut health? J. Anim. Feed Sci. 10, 47-56 